\title{
ZnII Complexes Based on Hybrid N-Pyrazole, N9-imine Ligands: Synthesis, X-Ray Crystal Structure, NMR Characterisation, and 3D Supramolecular Properties
}

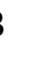

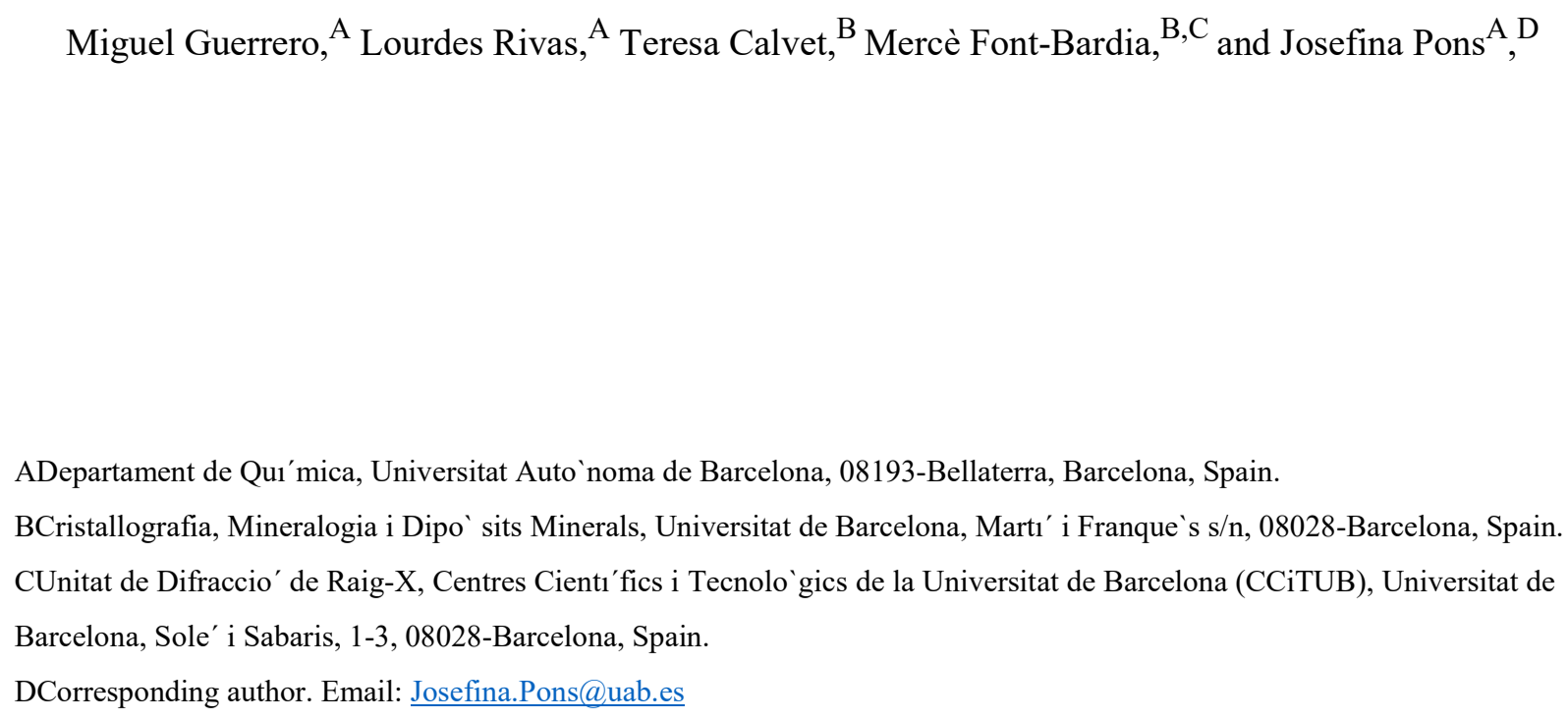


28 ABSTRACT:

30 The present report is on the synthesis of two new 3-imine-3,5-dimethylpyrazole ligands, N-[3-(3,5-

31 dimethyl-1H-pyrazol-1-yl)propylidene]ethylamine (L1) and N-[3-(3,5-dimethyl-1H-pyrazol-1-

32 1)propylidene]propylamine (L2). These ligands form molecular complexes with the formula [ZnCl2(L)]

$33\left(\mathrm{~L}^{1 / 4 \mathrm{~L}} 1(1)\right.$ and $\left.\mathrm{L} 2(2)\right)$ when the reacting with $\mathrm{ZnCl} 2$ in a metal $(\mathrm{M}) /$ ligand $(\mathrm{L})$ ratio of $1: 1$. These new

34 ZnII complexes have been characterised by elemental analyses, conductivity measurements, mass

35 spectrometry, and infrared, $1 \mathrm{H}$ and $13 \mathrm{C}\{1 \mathrm{H}\}$ NMR spectroscopy techniques. The two crystalline

36 structures of complexes 1 and 2 have been solved by X-ray diffraction methods. Finally, we have

37 studied the self-assembly three-dimensional supramolecular structure through different intra- and

38 intermolecular contacts. The application of these ZnII complexes in supramolecular crystal engineering

39 is interesting due to (1) the easy preparation and the high efficiency of this system and (2) the different

40 bonding properties of the heteroatoms ( $\mathrm{N}$-pyrazole vs $\mathrm{N}$-imine) present in the structure of the ligands. 


\section{INTRODUCTION}

49 The construction of molecular architectures[1] depends mostly on the combination of several factors

50 such as the coordination geometry of the metal ions, nature of the organic ligands and counterions, and

51 ratio between the metal salts and ligands, among others. One of the most interesting aspects of

52 coordination chemistry is the design of hybrid ligands, which are able to distinguish between different

53 metals depending on the reaction conditions.[2] The complexes, including pyrazolic ligands, are present

54 in many pharmacologically important compounds,[3] macromolecular chemistry,[4] and homogeneous

55 catalysis.[5] Particularly, group 12 metals $(\mathrm{Zn}, \mathrm{Cd}$, and $\mathrm{Hg}$ ) are promising due to their wide variety of

56 coordination numbers and geometries provided by the $\mathrm{d} 10$ configuration of the metal centre.[6]

57 In the recent past years, our research group has focussed its interest on the synthesis and characterisation

58 of heterotopic ligands containing a N-pyrazole group with other donor group such as P-phosphine

59 (N,P),[7] P 0-phosphinite (N,P0),[8]O-alcohol (N,O),[9] S-thioether (N,S),[10] or N-amine (N,N0).[11]

60 As an extension to these results, in the present paper, we report the synthesis of new pyrazole-derived

61 ligands with an imine group: N-[3-(3,5-dimethyl-1H-pyrazol-1-yl)propylidene] ethylamine (L1) and N-

62 [3-(3,5-dimethyl-1H-pyrazol-1-yl) propylidene]propylamine (L2). The L1 and L2 ligands contain one

63 nitrogen pyrazole and one imine nitrogen as potential N-donor atoms (Scheme 1). We also describe the

64 study of their reactivity with $\mathrm{ZnII}$, isolating complexes [ $\mathrm{ZnCl} 2(\mathrm{~L})](\mathrm{L} 1 / 4 \mathrm{~L} 1$ (1) and $\mathrm{L} 2$ (2)). Complete

65 characterisation of L1 and L2 and their ZnII complexes are reported, focusing on NMR studies

66 discussion, crystallographic structures, and self-assembly threedimensional (3D) arrangements.

67 
Synthesis and Characterisation of the Ligands New 3-imino-3,5-dimethylpyrazole ligands (L1 and L2) were prepared following similar procedures as described in the literature.[12] The synthetic procedure for the preparation of the L1 and L2 ligands consists of two steps (Scheme 1). First, 3,5dimethylpyrazolewas reacted with acrolein in dry dioxane to give the 3-(3,5-dimethyl-1H-pyrazol-1yl)propanal (Scheme 1a).[13] In the second step, the corresponding amine (ethylamine (L1) or propylamine (L2)) dissolved in water was added to generate the L1 and L2 ligands (Scheme 1b). The ligands were obtained as pure products $(62 \%(\mathrm{~L} 1)$ and $95 \%(\mathrm{~L} 2)$ yields).The ligands have been fully characterised by melting points, elemental analyses mass spectrometry, and infrared (IR), $1 \mathrm{H}, 13 \mathrm{C}\{1 \mathrm{H}\}$ NMR spectroscopy techniques. The NMR signals were assigned by reference to the literature[14] and from the analysis of DEPT, COSY, and HMQC spectra.

Elemental analyses, mass spectrometry, and all spectroscopic data for L1 and L2 are consistent with the proposed formulae. The positive ionisation spectra (ESI $p-M S$; electrospray ionisation mass spectroscopy) of L1 and L2 ligands measured in acetonitrile display a peak attributable to [LpNa] $\mathrm{p}$ $(\mathrm{L} 1 / 4 \mathrm{~L} 1, \mathrm{~L} 2)$. In the IR spectra of the two ligands, the characteristic absorptions measured using $\mathrm{NaCl}$ pellets observed at $1667 \mathrm{~cm} \quad 1$ are attributed to $\mathrm{n}\left(\mathrm{C}^{1} / 4 \mathrm{Nim}\right)(\mathrm{L} 1, \mathrm{~L} 2), 1553 \mathrm{~cm} \quad 1$ are attributed to the pyrazolyl group $\left[\mathrm{n}\left(\mathrm{C}^{1} / 4 \mathrm{C}\right), \mathrm{n}\left(\mathrm{C}^{1} / 4 \mathrm{~N}\right)\right] \mathrm{pz}(\mathrm{L} 1, \mathrm{~L} 2)$, and $773 \mathrm{~cm} \quad 1$ are attributed to $\mathrm{d}(\mathrm{C}-\mathrm{H})$ oop $(\mathrm{L} 1, \mathrm{~L} 2)$, confirming the presence of the imine group in the structure of the ligand. The NMR spectra were recorded in $\mathrm{CDCl} 3$ for the ligands. In the 1H NMR spectra, characteristic signals appear at $5.72 \mathrm{ppm}(\mathrm{L} 1)$ and $5.74 \mathrm{ppm}$ (L2), attributable to CHpz. Other signals are attributed to $\mathrm{NpzCH} 2 \mathrm{CH} 2 \mathrm{CH}^{1} / 4 \mathrm{Nim}$ that appear at $7.65 \mathrm{ppm}(\mathrm{L} 1, \mathrm{~L} 2)$. In the $13 \mathrm{C}\{1 \mathrm{H}\} \mathrm{NMR}$, the most important signals appear at $105.1 \mathrm{ppm}$ (L1) and $105.0 \mathrm{ppm}$ (L2), which correspond to CHpz, and $160.7 \mathrm{ppm}$ (L1) and $161.1 \mathrm{ppm}(\mathrm{L} 2)$, attributable to $\mathrm{NpzCH} 2 \mathrm{CH} 2 \mathrm{CH}^{1} / 4 \mathrm{Nim}$. Synthesis and Characterisation of the Complexes Complexes [ $\mathrm{ZnCl} 2(\mathrm{~L})](\mathrm{L} 1 / 4 \mathrm{~L} 1$ (1) and L2 (2)) were obtained by treatment of the corresponding ligand (Scheme 1c) with $\mathrm{ZnCl} 2$ in a $1: 1$ or $1: 2$ metal (M)/ligand (L) molar ratio in absolute ethanol for $24 \mathrm{~h}$. Interestingly, stoichiometry of the complexes does not depend of the $\mathrm{M} / \mathrm{L}$ molar ratio. Several techniques were used for the characterisation of all complexes: elemental analyses, mass spectrometry, conductivity measurements, and IR, and onedimensional (1D) and two-dimensional (2D) NMR spectroscopy techniques. In addition, a full 3D structure determination for compounds 1 and 2 was performed through singlecrystal X-ray diffraction method. The elemental analyses for compounds 1 and 2 are consistent with the formula [ $\mathrm{ZnCl} 2(\mathrm{~L})]$. The positive ionisation spectra (ESIp-MS), in acetonitrile, of compounds 1 and 2 give a peak attributable to $[\mathrm{ZnCl}(\mathrm{L})] \mathrm{p}(\mathrm{L} 1 / 4 \mathrm{~L} 1(1), \mathrm{L} 2(2))$. The spectrum of complex 1 also shows another peak at $\mathrm{m} / \mathrm{z} 218$ (100 $\%$ ), corresponding to [ZnCl2(L1)-3,5-Me2pz]. Molecular peaks of the cations are observed with the same isotope distribution as the theoretical ones. Moreover, conductivity values in methanol for 
complexes 1 and 2 are in agreement with the presence of non-electrolyte compounds because reported values (59 O $1 \mathrm{~cm} 2 \mathrm{~mol} \quad 1$ (1) and $61 \mathrm{O} \quad 1 \mathrm{~cm} 2 \mathrm{~mol} \quad 1(2))$ are lower than $80 \mathrm{O} \quad 1 \mathrm{~cm} 2 \mathrm{~mol}$ 1.[15]

The IR spectra of the two complexes in $\mathrm{KBr}$ pellets display absorptions of the 3-imine-3,5dimethylpyrazole ligands. For all complexes, the most characteristic bands are those attributable to the pyrazolyl group: $\left[\mathrm{n}\left(\mathrm{C}^{1 / 4 C}\right), \mathrm{n}\left(\mathrm{C}^{1 / 4 \mathrm{~N}}\right)\right] \mathrm{pz}$ at $1554 \mathrm{~cm} \quad 1(1)$ and $1551 \mathrm{~cm} \quad 1(2)$, and $\mathrm{d}(\mathrm{C}-\mathrm{H})$ oop at 802 $\mathrm{cm} \quad 1(1)$ and $794 \mathrm{~cm} \quad 1$ (2), and other characteristic bands are those attributable to $\mathrm{n}\left(\mathrm{C}^{1} / 4 \mathrm{Nim}\right)$ at 1666 $\mathrm{cm} \quad 1$ (1) and $1664 \mathrm{~cm} \quad 1$ (2).[14 ] This band is shifted to the lower frequencies relative to that of the free ligand upon coordination of the nitrogen atoms.

The $1 \mathrm{H}, 13 \mathrm{C}\{1 \mathrm{H}\} \mathrm{NMR}, \mathrm{DEPT}, \mathrm{COSY}, \mathrm{HMQC}$, andNOESY spectra were recorded in $\mathrm{CDCl} 3$ for the two complexes are discussed. $1 \mathrm{H}$ and $13 \mathrm{C}\{1 \mathrm{H}\}$ NMR spectra were consistent with the proposed formulation and showed the coordination of the ligands (L1 and L2) to the $\mathrm{Zn}$ atom. NMR spectroscopic data are reported in the Experimental section. For compounds 1 and 2, the study of the Npz-CH2-CH2$\mathrm{CH}^{1} / 4 \mathrm{Nim}$ fragments as AA0XX0 systems gave a set of coupling constants for each compound. These constants were consistent with the simulated spectra for compounds 1 and 2, obtained with the aid of the gNMR program.[16] All these results are reported in Table 1. Fig. 1 shows the experimentally determined and simulated spectra for 1 .

In the $1 \mathrm{H}$ NMR spectra of 1 and 2 at room temperature, the methylene protons for Npz-CH2-CH2$\mathrm{CH}^{1} / 4 \mathrm{Nim}$ chain appear as two bands. One is a well-defined band (doublet of doublet of doublets) at $\mathrm{d}^{1} / 44.84 \mathrm{ppm}$ (1) and $4.86 \mathrm{ppm}$ (2) and other is a broad band at $\mathrm{d}^{1} / 42.94 \mathrm{ppm}$ (1) and $2.93 \mathrm{ppm}$ (2). This suggests that at $298 \mathrm{~K}$, there is a fluxional process in which, with ringflipping, the two hydrogens of each $\mathrm{CH} 2$ are interconverted and only one signal can be observed. HMQC spectra were used to assign the signals of protons H-8 and H-9.

As observed from the NOESY spectra, the methyl linked to the pyrazole at $\mathrm{d}^{1} / 42.28 \mathrm{ppm}$ (1) and (2) showsNOEinteractions with $\mathrm{d}^{1} 1 / 44.84 \mathrm{ppm}$ (1) and $4.86 \mathrm{ppm}$ (2), but not with the ones at $\mathrm{d}^{1 / 42.94} \mathrm{ppm}$ (1) and $2.93 \mathrm{ppm}$ (2). The other signal is attributable to $\mathrm{Npz}-\mathrm{CH} 2-\mathrm{CH} 2-\mathrm{C} 1 / 4 \mathrm{Nim}$, which appears at $7.95 \mathrm{ppm}$ in both complexes.

Crystal Structures of the Complexes [ZnCl2(L)] (L5L1 (1), L5L2 (2))

For complexes 1 and 2, it has been possible to obtain colourless monocrystals suitable for X-ray analyses through crystallisation from dichloromethane/diethyl ether $(1: 1)$ mixture.

The structures consist of discrete $\mathrm{ZnII}$ molecules linked by diverse intermolecular interactions. It is important to mention that complex 2 contains two symmetrically independent molecules and two water solvent molecules in the unit cell. The environment around the $\mathrm{ZnII}$ centre in both complexes consists of two chlorine atoms and one ligand L (L1 (1) or L2 (2)) coordinated by (Npz, Nim), building a sevenmembered metallocycle whose conformation can be described as deformed half chair (Figs 2 and 3, respectively). The ZnII centre adopts a pseudo tetrahedral coordination, where the tetrahedron is somewhat distorted by larger $\mathrm{Cl} \mathrm{Zn}-\mathrm{Cl}, \mathrm{N}-\mathrm{Zn}-\mathrm{Cl}$, and $\mathrm{N}-\mathrm{Zn}-\mathrm{N}$ angles in comparison with the 
142 tetrahedral value (Table 2). The values of the angles for complexes 1 and 2 are in agreement with the

143 values reported in the literature for tetrahedral species $\mathrm{Npz}-\mathrm{Zn}-\mathrm{Cl}(101.38-122.98), \mathrm{Nim}-\mathrm{Zn}-\mathrm{Cl}$

144 (102.98-120.08),[17] and $\mathrm{Cl} \quad \mathrm{Zn}-\mathrm{Cl}(112.08-116.18) .[18]$ The Zn-Npz, Zn-Nim, and Zn-Cl

145 distances in both complexes are in the known range for tetrahedral species: $\mathrm{Zn}-\mathrm{Npz}\left(1.94-2.17 \mathrm{~A}^{\circ}\right)$,

$146 \mathrm{Zn}-\mathrm{Nim}\left(1.98-2.09 \mathrm{~A}^{\circ}\right)$, and $\mathrm{Zn}-\mathrm{Cl}\left(2.18-2.37 \mathrm{~A}^{\circ}\right) \cdot[17,18]$

147 The ligands adopt an E-, Z-configuration in these complexes. The angle between the planes Zn-N1-N2-

148 C6 and Zn-N3-C8-C7-C6 is 58.938 for 1, and those between planes Zn1-N11-N12-C16 and Zn1-

149 N13-C18-C17-C16, and planes Zn2-N21-N22-C26 and Zn2-N23-C28-C27-C26 are 56.098 and

15054.358 , respectively, for 2. All these values indicate the V-shaped form of the complexes studied here.

151 The $[\mathrm{ZnCl} 2(\mathrm{Npz})(\mathrm{Nim})]$ core is present in two complexes in the literature.[19] As seen in Table 2, the

$152 \mathrm{Zn}-\mathrm{Nim}$ distances are significantly longer than the $\mathrm{Zn}-\mathrm{Npz}$ distances. The numbers of parameters

153 refined and other details regarding the refinement of the crystal structures of complexes 1 and 2 are

154 gathered in Table 3.

155 Extended Structures of the Complexes [ZnCl2(L)] (L5L1 (1), L5L2 (2)) In compound 1, the molecular

156 units are further linked with 2 equivalent units (Fig. 4) through intermolecular hydrogen bond bridges

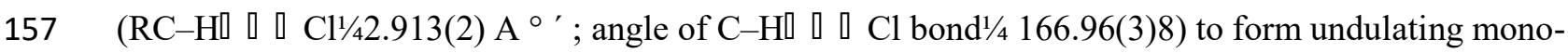

158 dimensional chains (Fig. 4a) along the a-axis leading to intermolecular $\mathrm{Zn} \square \square \square \mathrm{Zn}$ distances of

$1597.809(2) \mathrm{A}^{\circ}(1 \mathrm{p} \mathrm{x}, \mathrm{y}, \mathrm{z})$. Furthermore, complex 1 shows the cooperative intermolecular interaction C-

$160 \mathrm{H} \square \square \mathrm{Cl}$ between adjacent chains in the c-axis $\left(\mathrm{RC}-\mathrm{H} \square \square \square \mathrm{Cl} \mathrm{l}^{1} / 42.819(2) \mathrm{A}^{\circ}\right.$; angle of $\mathrm{C}-\mathrm{H} \square \square \square \mathrm{Cl}$

161 bond $1 / 4150.78(2) 8 ; x, 1 / 2 \quad y, 1 / 2 \mathrm{~b} \mathrm{z}$ ) (Fig. 4b, c) and $\mathrm{p}$ intermolecular interaction between C9-H9B

162 and the pyrazole ring ( $\mathrm{RC}-\mathrm{H} \square \square \square \mathrm{Cl} 1 / 42.790(2) \mathrm{A}^{\circ}$; ; angle of $\mathrm{C}-\mathrm{H} \square \square \square \mathrm{Cl}$ bond $1 / 4$ 156.66(2)8; - $\mathrm{x},-\mathrm{y}$,

$163-z$ ). All the intermolecular interactions together stabilise the 3D supramolecular network (Fig. 5).

164 Moreover, it is interesting to find that all the methyl groups are located on the external parts of the layer,

165 generating important hydrophobic interactions (Fig. 5). Among the non-covalent interactions,

166 hydrophobic interactions, usually existing among alkyl chains of biological macromolecules, are

167 difficult to be observed from a crystallographic perspective.[20]

168 The two independent (not symmetrically related) molecules of 2 are alternately packed forming chains

169 along the direction [010]. Inside these chains, the molecules are linked by hydrogen bonding between

170 the oxygen atoms of two water molecules and the four chloride atoms of the complexes (Fig. 6, Table

171 4). Furthermore, these chains are connected by weak interactions $\mathrm{C}-\mathrm{H} \square \square \square \mathrm{Cl}$ between molecules

172 related by symmetry of the neighbouring chains. Additionally, $p-p$ interactions can be observed between

173 pyrazole rings of the two alternated molecules along the [100] direction (Fig. 7). 


\section{CONCLUSIONS}

177 We have presented the reactivity of the new ligands 3-imino-3,5-dimethylpyrazole (L1 and L2) towards

$178 \mathrm{ZnCl}$. The study of the coordination of these ligands to $\mathrm{ZnII}$ has revealed the formation of molecular

179 complexes $[\mathrm{ZnCl} 2(\mathrm{~L})]\left(\mathrm{L}^{1 / 4 \mathrm{~L} 1}\right.$ (1) and L2 (2)). NMR studies have shown to be very useful in the

180 determination of the configuration of ligands in these complexes in solution; also, the single-crystal X-

181 ray diffraction method has allowed confirmation of the structures in solid state. Finally, we have studied

182 the 3D supramolecular structure through different intra- and intermolecular contacts leading to an easy

183 approach to obtain supramolecular crystal structures with different bonding properties of the

184 heteroatoms (N-pyrazole vs $\mathrm{N}$-imine) present in the structure of the ligands. 


\section{General Details}

The reactions were carried out under nitrogen atmosphere using vacuum line and Schlenk techniques. All reagents were of commercial grade and used without further purification. All solvents were dried and distilled by standard methods.

Elemental analyses $(\mathrm{C}, \mathrm{H}, \mathrm{N})$ were carried out by the staff of Chemical Analyses Service of the Universitat Auto 'noma de Barcelona on a Euro Vector 3100 instrument. Conductivity measurements were performed at room temperature (r.t.) in 10 3M methanol solution, employing a Ciber-Scan CON 500 (Euthech Instruments) conductometre. IR spectra were run on a Perkin-Elmer FT spectrophotometer, series 2000 as $\mathrm{NaCl}$ disks in the range of 4000-100 $\mathrm{cm} \quad 1$, and also recorded at the Chemical Analysis Service of the Universitat Autònoma de Barcelona on a Tensor 27 (Bruker) spectrometer, equipped with an attenuated total reflectance (ATR) accessory model MKII Golden Gate with diamond window in the range of 4000-600 cm 1. 1H NMR, 13C $\{1 \mathrm{H}\}$ NMR, COSY, HMQC, and NOESY spectra were recorded on a NMR-FT Bruker 250MHz spectrometer in CDCl3 solution at room temperature. All chemical shifts values (d) are given in ppm relative to TMS as internal standard. Mass spectra were obtained on an Esquire 3000 ion trap mass spectrometer from Bruker Daltonics. 3(3,5-Dimethyl-1H-pyrazol-1-yl)propanal was synthesised according to published methods.[13] Synthesis of 3-(3,5-Dimethyl-1H-pyrazol-1-yl)propanal Acrolein (C3H4O; $0.07 \mathrm{~mol}, 5 \mathrm{~mL}$ ) was added to 3,5-dimethylpyrazole $(0.05 \mathrm{~mol}, 4.85 \mathrm{~g})$ dissolved in $40 \mathrm{~mL}$ of dry dioxane

206 This solution was placed in a water bath at $408 \mathrm{C}$ for $24 \mathrm{~h}$. After the reaction concluded, the solvent was removed under vacuum. The product was purified by flash chromatography (silica gel $60 \mathrm{~A}^{\circ}$ ) with a mixture of ethyl acetate/dichloromethane $(1: 1)\left(\mathrm{RF}^{1 / 40.3}\right)$ as eluent, generating a yellow oil $(5.78 \mathrm{~g}, 76$ \%). nmax (NaCl)/cm 13082 (n(C-H)ar), 2921 (n(C-H)al), 1720 (n( $\left.\left(\mathrm{C}^{1 / 4 O}\right)\right), 1553\left(\mathrm{n}\left(\mathrm{C}^{1} / 4 \mathrm{C}\right)\right.$, n(C $\left.\left.\mathrm{C}^{1 / 4 \mathrm{~N}}\right)\right)$ pz, $1461\left(\mathrm{~d}\left(\mathrm{C}^{1 / 4 \mathrm{C}}\right), \mathrm{d}\left(\mathrm{C}^{1} / 4 \mathrm{~N}\right)\right)$ pz, 1423 (d(CH3)as), 1387 (d(CH3)s), 1021 (d(C-H)ip), 779 (d(C-H)oop). dH (CDCl3, $250 \mathrm{Mz}) 9.78$ (1H, t, 3J 0.9, NpzCH2CH2CHO), 5.73 (1H, s, CHpz), 4.22 (2H, t, 3J 6.6, NpzCH2CH2CHO), 3.02 (td, 2H, 3J 6.6, 0.9, NpzCH2CH2CHO), 2.24, 2.16 (3H, s, CH3(pz)). 13C $\{1 \mathrm{H}\}$ NMR (CDCl3, 63 MHz) 199.9 (NpzCH2CH2CHO), 147.9, 139.2 (CCH3), 105.1 (CH (pz)), 43.8 (NpzCH2CH2CHO), 41.4 (NpzCH2CH2CHO), 13.6, 11.1 (CCH3). m/z (ESI p) 175 (100 \%, C8H12N2O p Na p). Anal. Calc. for C8H12N2Ol 0.5H2O (161.2): C 59.61, H 8.12, N 17.38. Found: C 59.22, H 8.21, N $17.69 \%$. Dimethyl-1Hpyrazol- 1-yl)propylidene]propylamine (L2) The synthesis consists of the reaction between 3-(3,5-dimethyl- 1H-pyrazol-1-yl)propanal (10 mmnol, $1.52 \mathrm{~g})$ in $\mathrm{CH} 2 \mathrm{Cl} 2(7.5 \mathrm{~mL})$ and $10 \mathrm{mmol}$ of the appropriate amine (L1: ethylamine $70 \%, 0.80 \mathrm{mmol}$ or L2: propylamine $99 \%, 0.83 \mathrm{mmol})$ in water $(7.5$ $\mathrm{mL}$ ). The mixture was stirred at room temperature for $3 \mathrm{~h}$ and extracted three times with $5 \mathrm{~mL}$ of $\mathrm{CH} 2 \mathrm{Cl} 2$. The organic phase was collected and dried overnight with anhydrous $\mathrm{Na} 2 \mathrm{SO} 4$. The solution 
was filtered off and the solvent was removed under vacuum. The L1 and L2 ligands were obtained as white solids.

L1: Yield: $1.11 \mathrm{~g}$ (62 \%), mp 40-428C. nmax (NaCl)/cm 13121 (n(C-H)ar), 2967, 2928, 2869 (n(CH)al), 1667 (n( $\left.\left.\mathrm{C}^{1 / 4} \mathrm{Nim}\right)\right), 1553\left(\mathrm{n}\left(\mathrm{C}^{1} / 4 \mathrm{C}\right), \mathrm{n}\left(\mathrm{C}^{1} / 4 \mathrm{~N}\right)\right) \mathrm{pz}, 1461\left(\mathrm{~d}\left(\mathrm{C}^{1} / 4 \mathrm{C}\right), \mathrm{d}\left(\mathrm{C}^{1} / 4 \mathrm{~N}\right)\right) \mathrm{pz}, 1423(\mathrm{~d}(\mathrm{CH} 3) \mathrm{as})$, 1384 (d(CH3)s), 1022 (d(C-H)ip), 773 (d(C- H)oop). dH (CDCl3, $250 \mathrm{MHz}) 7.65$ (1H, t, 3J 4.1, $\left.\mathrm{NpzCH} 2 \mathrm{CH} 2 \mathrm{CH}^{1} / 4 \mathrm{Nim}\right), 5.72(1 \mathrm{H}, \mathrm{s}, \mathrm{CHpz}), 4.17$ (2H, t, 3J 7.3, $\left.\mathrm{NpzCH}_{2} \mathrm{CH} 2 \mathrm{CH}^{1} / 4 \mathrm{Nim}\right), 3.30$ (2H, q, 3J 7.4, NimCH2CH3), 2.69 (td, 2H, 3J 7.3, 3J 4.1, NpzCH2CH2CH1/4Nim), 2.19, 2.17 (3H, s, CH3(pz)), 1.13 (3H, t, 3J 7.4,NimCH2CH3). dC (CDCl3, $63 \mathrm{MHz}) 160.7$ (NpzCH2CH2CH1/4Nim), 147.6, 138.9 (CCH3), 105.1 (CH (pz)), 55.7 (NimCH2CH3), 45.3 ( $\left.\mathrm{NpzCH}_{2} \mathrm{CH} 2 \mathrm{CH}^{1} / 4 \mathrm{Nim}\right), 36.3$ (NpzCH2CH2CH1/4Nim), 16.2 (NimCH2CH3), 13.7, 11.2 (CCH3). m/z (ESI p ) 202 (100 \%, L1 p Na p). Anal. Calc. for C10H17N3ם0.5H2O (188.3): C 63.80, H 9.64, N 22.32. Found: C 63.58, H 9.37, N $21.93 \%$.

L2:Yield: 1.83 g (95\%),mp45-478C. nmax (NaCl)/cm $13121(\mathrm{n}(\mathrm{C}-\mathrm{H}) \operatorname{ar}), 2958,2928,2873$ (n(C-)al), (d(CH3)s), 1022 (d(C-H)ip), 773 (d(C-H)oop). dH (CDCl3, 250MHz) 7.65 (1H, t, 3J 4.1, NpzCH2CH2CH1/4Nim), 5.74 (s, 1H, CHpz), 4.18 (t, 2H, 3J 7.1, NimCH2CH2CH3), 3.31 (td, 2H, 3J 6.9, 4J 0.9, NpzCH2CH2CH1/4Nim), 2.72 (2H, td, 3J 6.9, 3J 4.1, $\left.\mathrm{NpzCH}_{2} \mathrm{CH} 2 \mathrm{CH}^{1} / 4 \mathrm{Nim}\right), 2.21,2.18$ (3H, s, CH3(pz)), 1.57 (2H, sx, 3J 7.1, NimCH2CH2CH3), 0.84 (3H, t, 3J 7.1, NimCH2CH2CH3). dC (CDCl3, 63MHz) 161.1 (NpzCH2CH2CH¹/4Nim), 147.5, 138.9 (CCH3), 105.0 (CH(pz)), 63.4 ( $\left.\mathrm{NpzCH} 2 \mathrm{CH} 2 \mathrm{CH}^{1} / 4 \mathrm{Nim}\right), 45.2$ ( $\left.\mathrm{NimCH} 2 \mathrm{CH} 2 \mathrm{CH} 3\right), 36.3$ ( $\left.\mathrm{NpzCH}_{2} \mathrm{CH}_{2} \mathrm{CH}^{1} / 4 \mathrm{Nim}\right), 23.9$ (NimCH2CH2CH3), 13.6, 11.7 (CCH3), 11.1 (NimCH2CH2CH3). m/z (ESIp) 225 (100\%, L2 pNap). Anal. Calc. for C11H19N3ם 0.5H2O (202.3): C 65.29, H 9.98, N 20.77. Found: C 65.52, H 9.79, N $20.58 \%$.

Synthesis of the Complexes [ZnCl2(L)] (L5L1 (1); L2 (2))

A solution of $2.0 \mathrm{mmol}$ of the corresponding ligand (L1: $0.38 \mathrm{~g}$; L2: $0.40 \mathrm{~g}$ ) dissolved in $20 \mathrm{~mL}$ of absolute ethanol was added to a solution of $2.0 \mathrm{mmol}(0.28 \mathrm{~g})$ of $\mathrm{ZnCl} 2$ and $4 \mathrm{~mL}$ of triethyl orthoformate (for dehydration purposes) in $10 \mathrm{~mL}$ of the same solvent. The mixture was stirred for $18 \mathrm{~h}$. The solution was reduced to $5 \mathrm{~mL}$ and the precipitate appeared. The solid was filtered, washed with $5 \mathrm{~mL}$ of diethyl ether, and recrystallized with dichloromethane.

1: Yield: $0.25 \mathrm{~g}$ (39\%). Conductivity (2.4】 $10 \quad 3$ Min methanol): $59 \mathrm{O} \quad 1 \mathrm{~cm} 2 \mathrm{~mol} \quad 1 . \mathrm{nmax}$ (neat)/cm $1469(\mathrm{~d}(\mathrm{C} 1 / 4 \mathrm{~N}))$ pz, 1449 (d(CH3)as), 1392, 1381 (d(CH3)s), 1057 (d(C-H)ip), 802 (d(C-H)oop). dH (CDCl3, $250 \mathrm{MHz}) 7.95$ (1H, br, NpzCH2CH2CH1/4Nim), 5.94 (1H, s, CHpz), 4.84 (2H, m, $\left.\mathrm{NpzCH} 2 \mathrm{CH} 2 \mathrm{CH}^{1} / 4 \mathrm{Nim}\right), 3.93$ (2H, q, 3J 7.4, NimCH2CH3), 2.94 (2H, m, NpzCH2CH2CH¹/4Nim), 

278 (69\%, ZnCl(L1)p), 218 (100 \%, ZnCl2(L1)-3,5-Me2pz). Anal. Calc. C10H17Cl2N3Zn (315.6): C 38.06, H 5.43, N 13.32. Found: C 38.13, H 5.45, N 13.30\%.

2. Yield: $0.30 \mathrm{~g}$ (46\%). Conductivity (2.5ロ $10 \quad$ 3Min methanol): $61 \mathrm{O} \quad 1 \mathrm{~cm} 2 \mathrm{~mol} \quad 1 . \mathrm{nmax}(\mathrm{neat}) / \mathrm{cm}$ 13032 (n(C-H)ar), 2966, 2932 (n(C-H)al), 1664 (n(C (C1/4Nim)), 1551 (n(C1/4C), n ( $\left.\left.\mathrm{C}^{1 / 4} / 4 \mathrm{~N}\right)\right) \mathrm{pz}, 1468$ $\left(\mathrm{d}\left(\mathrm{C}^{1 / 4 C}\right), \mathrm{d}\left(\mathrm{C}^{1 / 4 \mathrm{~N}}\right)\right)$ pz, 1449 (d(CH3)as), 1384 (d(CH3)s), 1055 (d(C-H)ip), 794 (d(C-H)oop). dH (CDCl3, $250 \mathrm{MHz}) 7.95$ (1H, br, NpzCH2CH2CH1/4Nim), 5.94 (1H, s, CHpz), 4.86 (2H, m, $\mathrm{NimCH} 2 \mathrm{CH} 2 \mathrm{CH} 3), 3.93$ (2H, t, 3J 7.3, NpzCH2CH2CH¹/4Nim), 2.93 (2H, m, NpzCH2CH2CH¹/4Nim), 2.50, 2.28 (3H, s, CH3(pz)), 1.92 (2H, td, 3J 7.4, 3J 5.3, NimCH2CH2CH3), 0.94 (3H, t, 3J 7.4, NimCH2CH2CH3). dC (CDCl3, $63 \mathrm{MHz}) 169.7$ (NpzCH2CH2CH¹/4Nim), 152.0, 141.7 (CCH3), 107.8 (CH(pz)), 65.4 ( $\left.\mathrm{NpzCH}_{2} \mathrm{CH} 2 \mathrm{CH}^{1} / 4 \mathrm{Nim}\right), 42.1$ ( $\left.\mathrm{NimCH}_{2} \mathrm{CH} 2 \mathrm{CH} 3\right), 35.8$ ( $\left.\mathrm{NpzCH}_{2} \mathrm{CH}_{2} \mathrm{CH}^{1} / 4 \mathrm{Nim}^{2}\right), 23.8$ (NimCH2CH2CH3), 13.9, 11.9 (CCH3), 11.6 (NimCH2CH2CH3). m/z (ESI p) 292 (100 \%, ZnCl(L2) p). Anal. Calc. for C11H19C12N3Zn (329.6): C 40.09, H 5.81, N 12.75. Found: C 40.11, H 5.92, N $12.82 \%$.

X-Ray Crystal Structures for Compounds 1 and 2

Tests with several solvents were conducted, but it was not possible to obtain single crystals of suitable quality. Although with some indications of being slightly twinned in the case of compound 2 , eventually, crystals of compounds 1 and 2 were selected through recrystallisation from $\mathrm{CH} 2 \mathrm{Cl} 2$ and diethyl ether mixture.

Data for 1 and 2 were collected on a MAR 345 diffractometer with an image plate detector. Unit cell parameters were determined from 890 reflections for compound 1 and 121 reflections for $2(38, \mathrm{y}, 318)$, and refined by least-squares method. Intensities were collected with graphite monochromatised MoKa radiation using v/2y scan technique. For 1,12674 reflections were measured in the range of $2.318 \# y \# 32.358 ; 4152$ ofwhich were non-equivalent by symmetry (Rint (on I) $1 / 40.082$ ). Lorentz polarisation and absorption corrections were made; and 2598 reflections were assumed as observed by applying the condition I $\$ 2 \mathrm{~s}(\mathrm{I})$. For 2, 26213 reflections were measured in the range of 1.768\#y\#32.408; 9183 of which were non-equivalent by symmetry (Rint (on I)1/40.064); and 4616 reflections were assumed as observed by applying the condition I $\$ 2 \mathrm{~s}(\mathrm{I})$.

Both structures were solved by direct methods using SHELXS computer program (SHELXS-97) and refined by full matrix least-squares method with SHELXL-97 computer program using 12674 reflections for 1 and 987 for 2 . For 1, the minimised function was $\mathrm{Sw}|| \mathrm{Fo}|2 \quad| \mathrm{Fc}|2| 2$, where $\mathrm{w}^{1 / 4}[\mathrm{~s} 2(\mathrm{I}) \mathrm{p}$ (0.00449P)2] 1 and $\mathrm{P} 1 / 4(|\mathrm{Fo}| 2 \mathrm{p} 2|\mathrm{Fc}| 2) 2 / 3$. For 2, the minimised functionwasSw || $\mathrm{Fo}|2 \quad| \mathrm{Fc}|2| 2$, wherew $1 / 4[\mathrm{~s} 2(\mathrm{I}) \mathrm{p}(0.00488 \mathrm{P}) 2] \quad 1$ and $\mathrm{P}^{1} / 4(|\mathrm{Fo}| 2 \mathrm{p} 2|\mathrm{Fc}| 2) 2 / 3$. The $\mathrm{H}$ atoms were included in the calculated position and constrained for compound 1, and mixed for compound 2.[21] The finalR(F) factor andRw(F2)values aswell as the number of parameters refined and other details regarding the refinement of the crystal structures are gathered in Table 3. 
297

298 
301 This work has been supported by MAT2011-27225 and the 2009SGR76 projects are acknowledged. L.

302 R. also acknowledges the Universitat Auto`noma de Barcelona for their pre-doctoral grant.

303 


\section{REFERENCES}

[1] (a) L. E. Kreno, K. Leong, O. K. Farha, M. Allendorf, R. P. Van Duyne, J. T. Hupp, Chem. Rev. 2012, 112, 1105. doi:10.1021/CR200324T (b) A. A. Talin, A. Centrone, A. C. Ford, M. E. Foster, V. Stavila, P. Haney, R. A. Kinney, V. Szalai, F. Gabaly, H. P. Yoon, F. Le'onard, M. D. Allendorf, Science 2014, 343, 66. doi:10.1126/SCIENCE.1246738

[2] (a) P. Cordier, F. Tournilhac, C. Soulie-Zikovic, L. Liebler, Nature 2008, 451, 977. doi:10.1038/NATURE06669 (b) H. J. Schneider, R. M. Strongin, Accounts Chem. Res. 2009, 42, 1489. doi:10.1021/AR800274U (c) N. N. Adarsh, P. Dastidar, Chem. Soc. Rev. 2012, 41, 3039. doi:10.1039/C2CS15251G (d) N. Robertson, L. Cronin, Coord. Chem. Rev. 2002, 227, 93. doi:10.1016/S0010-8545(01)00457-X (e) E. Lindler, T. Schneller, F. Auer, H. A. Mayer, Angew. Chem., Int. Ed. 1999, 38, 2155. (f) V. V. Grushin, Chem. Rev. 2004, 104, 1629. doi:10.1021/CR030026J (g) A. L. Gavrilova, B. Bosnich, Chem. Rev. 2004, 104, 349. doi:10.1021/CR020604G

[3] (a) J. Pons, J. Ros, M. Llagostera, J. A. Pe'rez, M. Ferrer, Spanish Patent 01494 2003. (b) R. W.Y. Sun, D. L. Ma, E. L.-M. Wong, C. M. Che, Dalton Trans. 2007, 4884. (c) A. Satake, T. Nakata, J. Am. Chem. Soc. 1998, 120, 10391. doi:10.1021/JA982269C (d) C. NavarroRanninger, L. Lo'pez-Solera, V. M. Gonza'lez, J. M. Pe'rez, A. Alvarez-Valdes, A. Martı'n, P. R. Raithby, J. R. Massager, C. Alonso, Inorg. Chem. 1996, 35, 5181. doi:10.1021/IC960050Y (e) K. Sakai, Y. Tomita, T. Ue, K. Goshima, M. Ohminato, T. Tsubomura, K. Matsumoto, K. Ohmura, K. Kawakami, Inorg. Chim. Acta 2000, 297, 64. doi:10.1016/S0020-1693(99)00287-X

[4] (a) M. Guerrero, J. Pons, V. Branchadell, T. Parella, X. Solans, M. Font-Bardı'a, J. Ros, Inorg. Chem. 2008, 47, 11084. doi:10.1021/IC8013915 (b) A. de Leo'n,M. Guerrero, J. Garc1'aAnto'n, J. Ros, M. Font-Bardı'a, J. Pons, CrystEngComm 2013, 15, 1762. doi:10.1039/C2CE26687C (c) J. J. Neuman, M. Suri, G. Frank, Angew. Chem., Int. Ed. Engl. 2010, 49, 7790. doi:10.1002/ANIE.201002389 (d) M. Guerrero, J. A. Pe'rez, T. Calvet, M. Font-Bardı'a, J. Pons, Aust. J. Chem. 2013, 66, 685. doi:10.1071/CH13021 (e) J. M. Lehn, 
Science 1993, 260, 1762. doi:10.1126/SCIENCE. 8511582 (f) C. A. Mirkin, M. A. Ratner, Annu. Rev. Phys. Chem. 1992, 43, 719. doi:10.1146/ANNUREV.PC.43.100192.003443

333

334

335

336

(a) J. Pe'rez, L. Riera, Eur. J. Inorg. Chem. 2009, 4913. doi:10.1002/ EJIC.200900694 (b) M. Guerrero, J. Pons, J. Ros, J. Organomet. Chem. 2010, 695, 1957. doi:10.1016/J.JORGANCHEM.2010.05.012 (c) V. Montoya, J. Pons, V. Branchadell, J. Garcı'a-Anto'n, X. Solans, M. Font-Bardı'a, J. Ros, Organometallics 2008, 27, 1084. doi:10.1021/ OM7009182 (d) J. Y. Lee, O. K. Farha, J. Roberts, K. Scheidt, S. T. Nguyen, J. T. Hupp, Chem. Soc. Rev. 2009, 38, 1450. doi:10.1039/B807080F (e) D. Peral, F. Go'mezVillarraga, X. Sala, J. Pons, J. C. Bayo'n, J. Ros, M. Guerrero, L. Vendier, P. Lecante, J. Garcı'a-Anto'n, K. Philippot, Catal. Sci. Technol. 2013, 3, 475. doi:10.1039/C2CY20517C (f) S. Ojwach, J. Darkwa, Inorg. Chim. Acta 2010, 363, 1947. doi:10.1016/J.ICA.2010.02.014

[6] (a) J. Yang, B. Wu, F. Y. Zhuge, J. J. Liang, C. D. Jia, Y. Y. Wang, N. Tang, X. J. Yang, Q. Z. Shi, Cryst. Growth Des. 2010, 10, 2331. doi:10.1021/CG100093N (b) H. Fleischer, Y. Dienes, B.Mathiasch, V. Schmitt, D. Schollmeyer, Inorg. Chem. 2005, 44, 8087. doi:10.1021/IC050814M (c) M. Guerrero, J. Pons, M. Font-Bardia, T. Calvet, J. Ros, Polyhedron 2010, 29, 1083. doi:10.1016/J.POLY.2009.11.018

(a) S. Muñz, J. Pons, J. Ros, C. A. Kilner, M. A. Halcrow, J. Organomet. Chem. 2011, 696, 2736. doi:10.1016/J.JORGANCHEM.2011. 04.019 (b) G. Esquius, J. Pons, R. Ya'ñez, J. Ros, R. Mathieu, N. Lugan, B. Donnadieu, J. Organomet. Chem. 2003, 667, 126. doi:10.1016/S0022328X(02)02156-3 (c) G. Esquius, J. Pons, R. Ya'ñez, J. Ros, R. Mathieu, B. Donnadieu, N. Lugan, Eur. J. Inorg. Chem. 2002, 2999. doi:10.1002/1099-0682 (200211)2002:11,2999::AIDEJIC2999.3.0.CO;2-A

[8] (a) S. Muñoz, M. Guerrero, J. Ros, T. Parella, M. Font-Bardı'a, J. Pons, Cryst. Growth Des. 2012, 12, 6234. doi:10.1021/CG3014333 (b) S. Muñoz, J. Pons, J. Garc1'a-Anto'n, X. Solans, M. Font-Bard1'a, J. Ros, J. Coord. Chem. 2009, 62, 3940. doi:10.1080/ 00958970903208292 (c) S. Muñz, J. Pons, X. Solans, M. Font-Bardı'a, J. Ros, J. Organomet. Chem. 2008, 693, 2132. doi:10.1016/J.JORGANCHEM.2008.03.010 (d) R. Tribo', S. Muñoz, J. Pons, R. Ya'ñ̃ez, A. 
Alvarez-Larena, J. F. Piniella, J. Ros, J. Organomet. Chem. 2005, 690, 4072. doi:10.1016/ J.JORGANCHEM.2005.05.047

360

361

362

363

[9] (a) M. Guerrero, J. A. Pe'rez, M. Font-Bardı'a, J. Pons, J. Coord. Chem. 2013, 66, 3314. doi:10.1080/00958972.2013.837895 (b) J. A. Pe'rez, V. Montoya, J. A. Ayllo'n, M. FontBardi'a, T. Calvet, J. Pons, Inorg. Chim. Acta 2013, 394, 21. doi:10.1016/J.ICA. 2012.07.027 (c) M. Guerrero, J. Pons, J. Ros, M. Font-Bardı'a, O. Vallcorba, J. Rius, V. Branchadell, A. Merkoc,i, CrystEngComm 2011, 13, 6457. doi:10.1039/C1CE05626C (d) S. Muñoz, J. Pons, J. Ros, M. Font-Bardı'a, C. A. Kilner, M. A. Halcrow, Inorg. Chim. Acta 2011, 373, 211. doi:10.1016/J.ICA.2011. 04.027(e) C. Luque, J. Pons, T. Calvet, M. Font-Bardı'a, J. Garcı'aAnto'n, J. Ros, Inorg. Chim. Acta 2011, 367, 35. doi:10.1016/J.ICA.2010. 11.041 (f) V. Montoya, J. Pons, X. Solans, M. Font-Bardı'a, J. Ros, Inorg. Chim. Acta 2007, 360, 625. doi:10.1016/J.ICA.2006.08.058 (g) A. Boixassa, J. Pons, X. Solans, M. Font-Bardı'a, J. Ros, Inorg. Chim. Acta 2004, 357, 733. doi:10.1016/J.ICA.2003.06.015 (h) A. Boixassa, J. Pons, X. Solans, M. Font-Bardı'a, J. Ros, Inorg. Chim. Acta 2003, 355, 254. doi:10.1016/S00201693(03) 00346-3 (i) A. Boixassa, J. Pons, X. Solans, M. Font-Bardı'a, J. Ros, Inorg. Chim. Acta 2002, 340, 49. doi:10.1016/S0020-1693(02)01052-6

[10] (a) J. Garc1'a-Anto'n, J. Pons, X. Solans, M. Font-Bard1'a, J. Ros, Inorg. Chim. Acta 2004, 357, 571. doi:10.1016/J.ICA.2003.08.013 (b) J. Garc1'a-Anto'n, J. Pons, X. Solans, M. Font-Bard1'a, J. Ros, Inorg. Chim. Acta 2003, 355, 87. doi:10.1016/S0020-1693(03)00333-5 (c) J. Garc1'aAnto'n, J. Pons, X. Solans, M. Font-Bardı'a, J. Ros, Eur. J. Inorg. Chem. 2003, 2992. doi:10.1002/EJIC.200300035

[11] (a) M. C. Castellano, J. Pons, J. Garc1'a-Anto'n, X. Solans, M. Font-Bard1'a, J. Ros, Inorg. Chim. Acta 2008, 361, 2923. doi:10.1016/J.ICA. 2008.02.059 (b) J. Pons, J. Garc1'a-Anto'n, M. Font-Bardı'a, T. Calvet, J. Ros, Inorg. Chim. Acta 2009, 362, 2698. doi:10.1016/J.ICA.2008.12.009

[12] A. Simion, C. Simion, T. Kanda, S. Nagashima, Y. Mitoma, T. Yamada, K. Mimura, M. Tashiro, J. Chem. Soc., Perkin Trans 1 2001, 2001, 2071. doi:10.1039/B102749M 
[13] O. S. Attaryan, S. K. Antanosyan, F. S. Kinoyan, R. A. Tamazyan, G. A. Panosyan, S. G. Matsoyan, Russ. J. Org. Chem. 2006, 42, 1868. doi:10.1134/S1070428006120220

[14] (a) E. Pretsh, T. Clerc, J. Seibl, W. Simon, Tables of Determination of Organic Compounds. 13C NMR, 1H NMR, IR, MS, UV/Vis, Chemical Laboratory Practice 1989 (Springer-Verlag: Berlin, Germany). (b) D. H. Williams, I. Fleming, Spectroscopic Methods in Organic Chemistry 1995 (McGraw-Hill: London, UK).

[15] (a) L. K. Thompson, F. I. Lee, E. J. Gabe, Inorg. Chem. 1988, 27, 39.

doi:10.1021/IC00274A010 (b) W. J. Geary, Coord. Chem. Rev. 1971, 7, 81. doi:10.1016/S0010$8545(00) 80009-0$

[16] P. H. M. Butzelaar, g NMR ver. 4.0. IvorySoft 1997 (Cherwell Scientific: Oxford, UK).

[17] (a) C. Y. Wang, Acta Crystallogr., Sect.E: Struct. Rep. Online 2011, 67, m1085. doi:10.1107/S1600536811027085 (b) U. Ko“hn, M. Klopfleisch, H. Go“ rls, E. Anders, Tetrahedron: Asymmetry 2006, 17, 811. doi:10.1016/J.TETASY.2006.02.009 (c) U. Ko“hn, M. Schulz, H. Go“ rls, E. Anders, Tetrahedron: Asymmetry 2005, 16, 2125. doi:10.1016/J.TETASY.2005.04.023 (d) M. Amirnasr, A. H. Mahmoudkani, A. Gorji, S. Dehghanpour, H. R. Bijanzadeh, Polyhedron 2002, 21, 2733. doi:10.1016/S0277$5387(02) 01277-9$

[18] (a) S. Bieller, A. Haghiri, M. Bolte, J. W. Bats, M. Wagner, H. W. Lerner, Inorg. Chim. Acta 2006, 359, 1559. doi:10.1016/J.ICA.2005. 10.034 (b) A. M. Schuitema, M. Engelen, I. A. Koval, S. Gorter, W. L. Driessen, J. Reedijk, Inorg. Chim. Acta 2001, 324, 57. doi:10.1016/S0020-1693(01)00500-X (c) C. J. Tokar, P. B. Kettler, W. B. Tolman, Organometallics 1992, 11, 2737. doi:10.1021/OM00044A001 (d) M. Guerrero, J. Pons, T. Parella, M. Font-Bardı'a, T. Calvet, J. Ros, Inorg. Chem. 2009, 48, 8736. doi:10.1021/IC900908N

[19] (a) U. Ko“hn, M. Schulz, H. Go“ rls, E. Anders, Tetrahedron: Asymmetry 2005, 16, 2125. doi:10.1016/J.TETASY.2005.04.023 (b) U. Ko“hn, M. Schulz, H. Go“rls, E. Anders, Tetrahedron: Asymmetry 2006, 17, 811. doi:10.1016/J.TETASY.2006.02.009 
412 [20] (a) A. Ustinov, H. Weissman, E. Shirman, I. Pinkas, X. B. Zuo, B. Rybtchinski, J. Am. Chem. Soc. 2011, 133, 16201. doi:10.1021/JA2066225 (b) B. Bhayana, C. S. Wilcox, Angew. Chem., Int. Ed. 2007, 46, 6833. doi:10.1002/ANIE.200700932

415 [21] G. M. Sheldrick, Acta Crystallogr., Sect. A: Found. Crystallogr. 2008, 64, 112.

416 doi:10.1107/S0108767307043930

417 
420 Figure 1. 250MHz 1H NMR data obtained at 298K and the simulated g NMR spectra for the H8 and H9 protons of the Npz-CH2-CH2-CH1/4Nim fragment of [ $\mathrm{ZnCl} 2(\mathrm{~L} 1)](1)$.

422

423 Figure 2. ORTEP drawing of [ $\mathrm{ZnCl} 2(\mathrm{~L} 1)](1)$, showing all non-hydrogen atoms and the atom numbering scheme; $50 \%$ probability amplitude displacement ellipsoids are shown.

425

426 Figure 3. ORTEP drawing of [ $\mathrm{ZnCl} 2(\mathrm{~L} 2)]$ (2), showing all non-hydrogen atoms and the atom

427 numbering scheme; 50\% probability amplitude displacement ellipsoids are shown.

428

429

Figure 4. (Views of 1- and 2D layered supramolecular architectures of [ $\mathrm{ZnCl} 2(\mathrm{~L} 1)]$ (1) along the a430 direction, generated by $\mathrm{C}-\mathrm{H} \square \square \square \mathrm{Cl}$ intermolecular interactions..

431

432

Figure 5. View of 3D supramolecular architecture of $[\mathrm{ZnCl} 2(\mathrm{~L} 1)](1)$.

433

434 Figure 6. Views of 1D supramolecular chain of [ $\mathrm{ZnCl} 2(\mathrm{~L} 2)]$ (2) along the [010] direction, generated by $435 \mathrm{O}-\mathrm{H} \square[\square \mathrm{Cl}$ intermolecular interactions.

436

437 Figure 7. View of p-p intermolecular interaction between adjacent pyrazole rings of [ $\mathrm{ZnCl}$ (L2)] (2) 
(a)<smiles>C=CC(=O)C=CC=O</smiles>

(b)
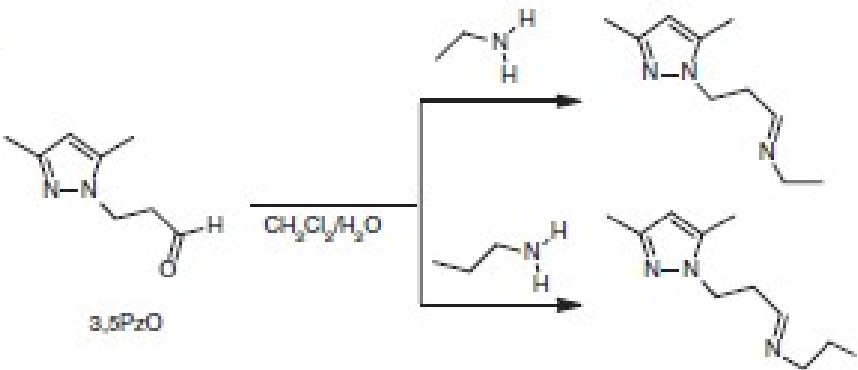

L1

(c)

$$
\text { L1-L2 } \left.\underset{\text { Ethand }}{\stackrel{\mathrm{ZnCl}}{2}} \quad\left[\mathrm{ZnCl}_{2}(\mathrm{~L})\right] \mathrm{L}=\mathrm{L}_{1}(1) ; \mathrm{L}_{2}(2)\right)
$$


FIGURE 1.

445

446

447

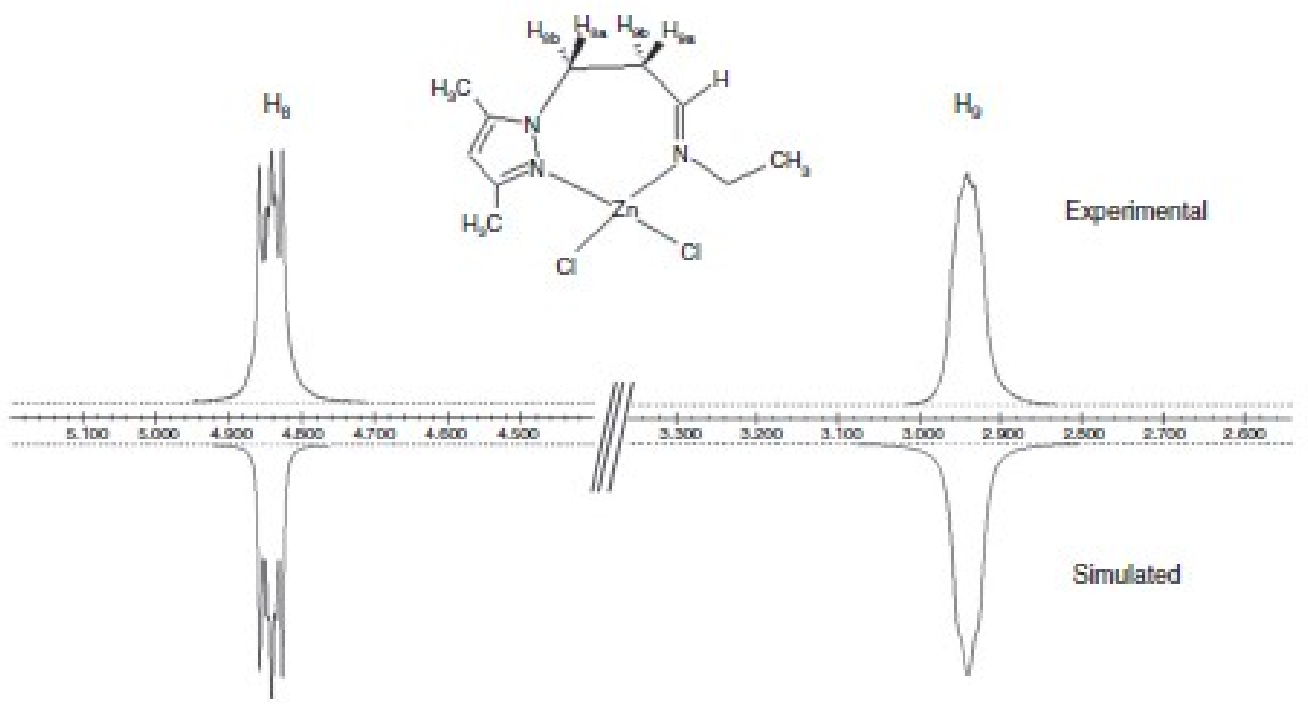

448 
FIGURE 2.

450

451

452

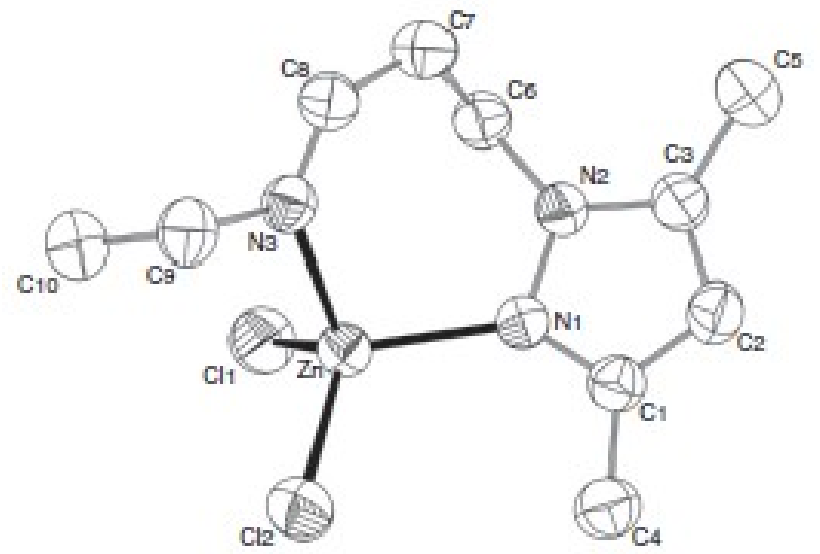

453

454 
FIGURE 3.

456

457

458

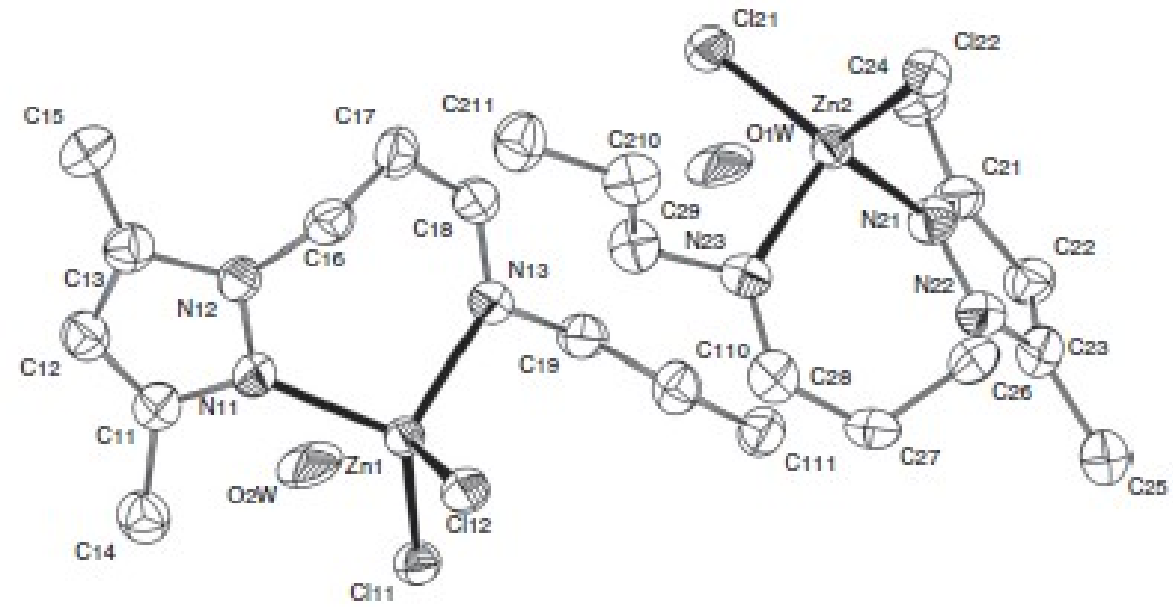

459 
FIGURE 4.

461

462
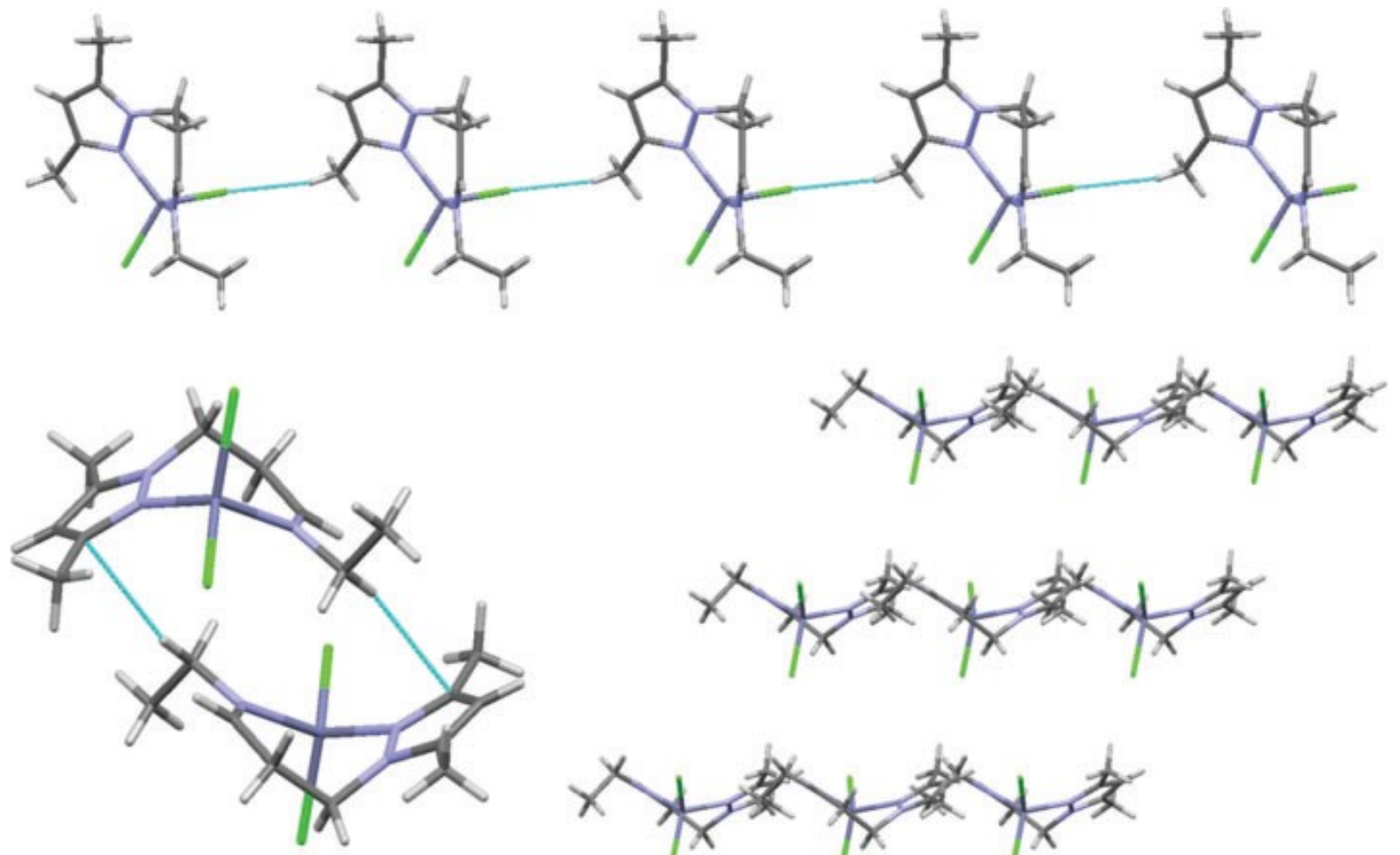

463

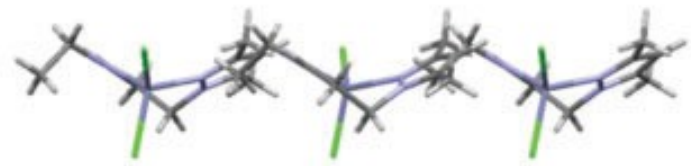

464

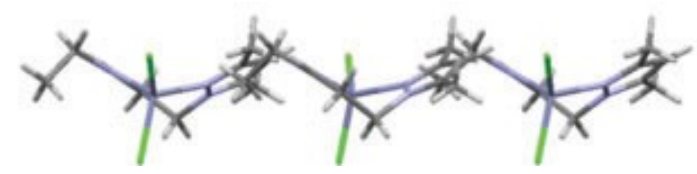


466

467

468

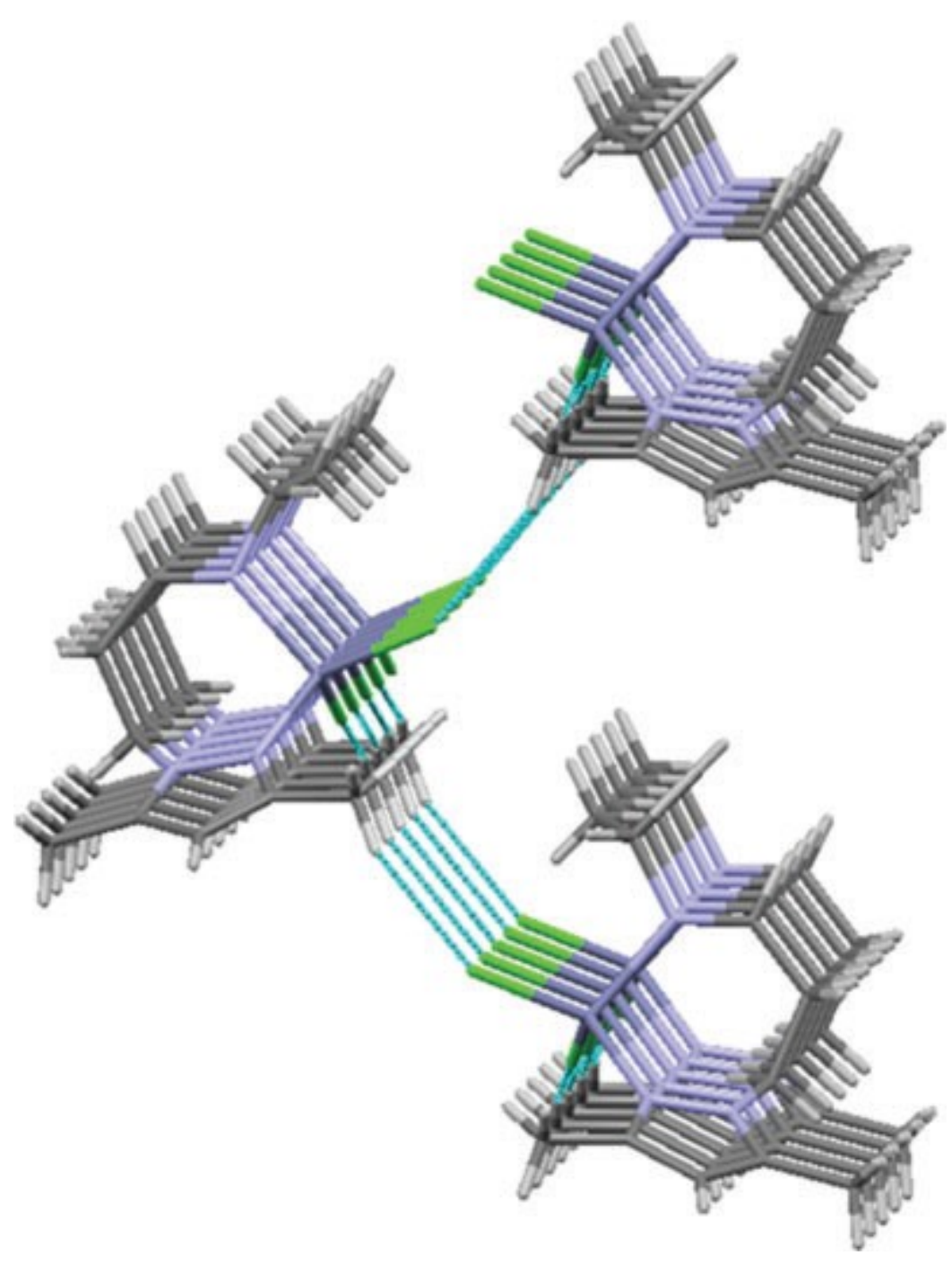

469 


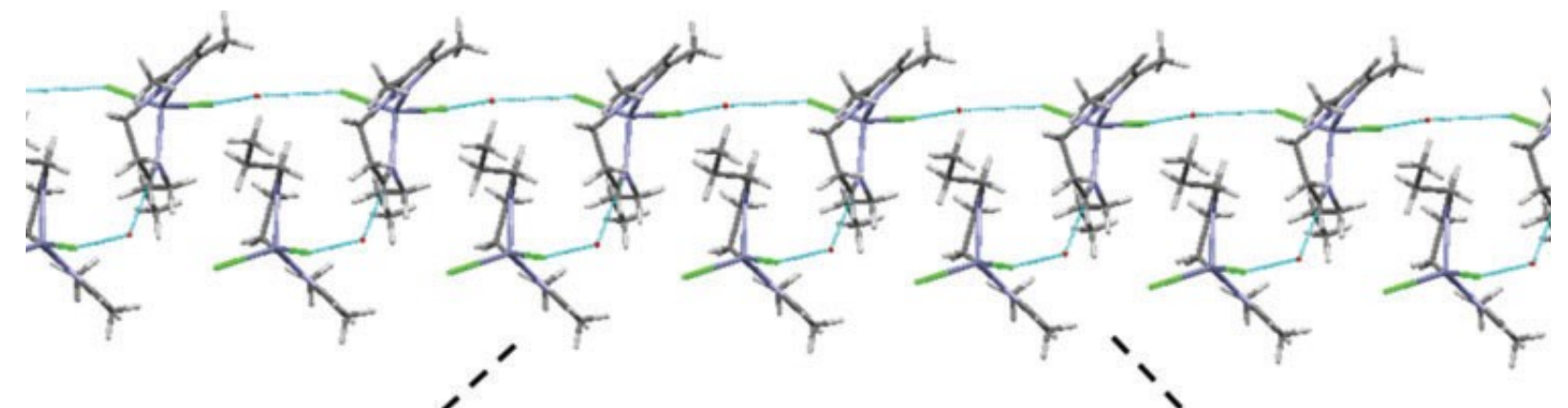


FIGURE 7

476

477

478

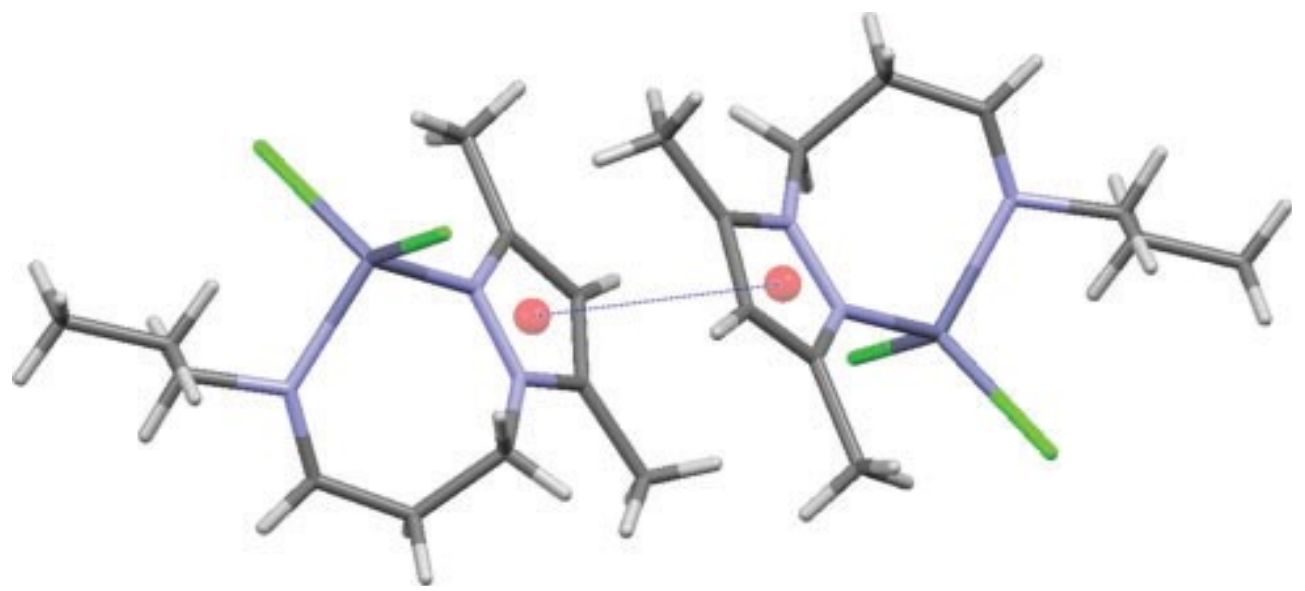

479 
480 Table 1. 1H NMR results: Chemical shifts $(\mathrm{d})$ and $1 \mathrm{H}, 1 \mathrm{H}$ coupling constants $(\mathrm{J})$ for 1 and 2 measured 481 in $\mathrm{CDCl} 3$ at $298 \mathrm{~K}$

\begin{tabular}{|c|c|c|}
\hline Compound & 1 & 2 \\
\hline $\mathrm{s} \mathrm{CH}_{2}(\mathrm{~s})[\mathrm{pm}]$ & 4.84 & 4.56 \\
\hline $\mathrm{s} \mathrm{CH}_{2}(9)[\mathrm{prm}]$ & 294 & 293 \\
\hline${ }^{2} T_{\max }[\mathrm{Hz}]$ & -12.5 & -123 \\
\hline${ }^{2} y_{\mathrm{an}}[\mathrm{Hz}]$ & -125 & -123 \\
\hline$V_{\text {hax }}[\mathrm{Hz}] ; S_{n, w}[\mathrm{~Hz}]$ & $7.18 ; 302$ & $720 ; 3.10$ \\
\hline$Y_{\operatorname{man}}[\mathrm{Hz}] ;{ }^{3 \mathrm{man}}[\mathrm{Hz}]$ & $7.18 ; 302$ & $7.20 ; 3.10$ \\
\hline
\end{tabular}


485 Table 2. Selected bond lengths $\left[\mathrm{A}^{\circ}\right]$ and bond angles [8] for 1 and 2

486

\begin{tabular}{|c|c|c|c|}
\hline & 1 & & \\
\hline $\mathrm{Zn}-\mathrm{N}(1)$ & $2.031(2)$ & & \\
\hline $\mathrm{Zn}-\mathrm{N}_{3}$ & $2.099(3)$ & & \\
\hline $\mathrm{Zn}-\mathrm{Cl}$ & $2.231(2)$ & & \\
\hline $\mathrm{Zn}-\mathrm{Cl}_{2}$ & $2.2356(14)$ & & \\
\hline $\mathrm{N} 1-7 \mathrm{n}-\mathrm{N} 3$ & $100.53(10)$ & & \\
\hline $\mathrm{N} 1-\mathrm{Zn}-\mathrm{Cl}$ & $113.56(8)$ & & \\
\hline $\mathrm{N} 3-\mathrm{Zn}-\mathrm{Cl}$ & $108.72(8)$ & & \\
\hline $\mathrm{N} 1-\mathrm{Zn}-\mathrm{C}_{2}$ & $111.02(8)$ & & \\
\hline $\mathrm{N}_{3}-\mathrm{Zn}-\mathrm{C}_{2}$ & $107.30(9)$ & & \\
\hline \multirow[t]{2}{*}{$\mathrm{C}_{1}-\mathrm{Zn}-\mathrm{C}_{2}$} & $114.54(5)$ & & \\
\hline & 2 & & \\
\hline $\mathrm{Znl-N11}$ & $2.028(4)$ & $\mathrm{Zn} 2-\mathrm{N} 21$ & $2070(4)$ \\
\hline $\mathrm{Znl}-\mathrm{N} 13$ & $2074(4)$ & $\mathrm{Zn} 2-\mathrm{N} 23$ & $2.067(5)$ \\
\hline $\mathrm{ZnI}-\mathrm{Cll} 1$ & $2.243(2)$ & $\mathrm{Zn} 2-\mathrm{C} 21$ & $2.227(2)$ \\
\hline $\mathrm{Zn} 1-\mathrm{Cl1} 2$ & $2.275(2)$ & $\mathrm{Zn} 2-\mathrm{a} 22$ & $2.184(2)$ \\
\hline N11-7n 1-N13 & $100.96(18)$ & $\mathrm{N} 21-\mathrm{Zn} 2-\mathrm{N} 23$ & $1023(2)$ \\
\hline $\mathrm{N} 11-\mathrm{Zn} 1-\mathrm{Cl} 11$ & $112.20(14)$ & $\mathrm{N} 2 \mathrm{I}-\mathrm{Zn} 2 \mathrm{Cl} 21$ & $108.74(14)$ \\
\hline N13- $2 \mathrm{n} 1-\mathrm{Cl11}$ & $108.38(13)$ & $\mathrm{N} 23-\mathrm{Zn} 2-\mathrm{Cl} 21$ & $103.83(15)$ \\
\hline $\mathrm{N} 11-\mathrm{Zn} 1-\mathrm{Cl} 12$ & $110.44(13)$ & $\mathrm{N} 21-\mathrm{Zn} 2-\mathrm{Cl} 22$ & $111.63(14)$ \\
\hline $\mathrm{N} 13-\mathrm{Zn} 1-\mathrm{Cl} 12$ & $109.49(13)$ & $\mathrm{N} 23-\mathrm{Zn} 2-\mathrm{Cl}_{2} 2$ & $109.57(14)$ \\
\hline $\mathrm{C} 11-\mathrm{Zn} 1-\mathrm{Cl1} 2$ & $114.46(\gamma)$ & $\mathrm{Cl}_{21} \mathrm{-} \mathrm{Zn} 2-\mathrm{Cl} 2$ & $119.19(7)$ \\
\hline
\end{tabular}


489 Table 3. Crystallographic data for compounds 1 and 2

490

\begin{tabular}{|c|c|c|}
\hline & 1 & 2 \\
\hline $\begin{array}{l}\text { Formulh } \\
\text { Formulh weight }\end{array}$ & $\begin{array}{l}\mathrm{C}_{10} \mathrm{H}_{17} \mathrm{O}_{2} \mathrm{~N}, 7 \mathrm{n} \\
315.53\end{array}$ & $\begin{array}{l}\mathrm{C}_{22} \mathrm{H}_{25} \mathrm{Cl}_{4} \mathrm{~N}_{6} \mathrm{OZ} \mathrm{n}_{2} \\
677.14\end{array}$ \\
\hline $\begin{array}{l}\text { Tampersure }[K] \\
\text { Wavelength }[\hat{H}]\end{array}$ & $\begin{array}{l}293(2) \\
0.71073\end{array}$ & $\begin{array}{l}293(2) \\
0.71073\end{array}$ \\
\hline $\begin{array}{l}\text { System, space group } \\
\text { Unit cell dimensions }\end{array}$ & Monoclinic, $P 2_{1} / c$ & Orthothombic, $P_{n=2} 2_{1}$ \\
\hline$a[\dot{\hat{L}}]$ & $\begin{array}{l}8.596(6) \\
14.933(7)\end{array}$ & $\begin{array}{l}23.177(10) \\
8.481(5)\end{array}$ \\
\hline$c[\hat{\mathcal{K}}]$ & $12869(7)$ & $15.229(5)$ \\
\hline$\beta[1]$ & $121.95(4)$ & 90 \\
\hline$V\left[\hat{K}^{3}\right]$ & 1495.7(15) & $2993(2)$ \\
\hline$z$ & 4 & 4 \\
\hline $\begin{array}{l}D_{c}\left[\mathrm{~g} \mathrm{~cm}^{-3}\right] \\
\mu\left[\mathrm{mm}^{-1}\right]\end{array}$ & $\begin{array}{l}1.500 \\
2.112\end{array}$ & $\begin{array}{l}1.502 \\
1.986\end{array}$ \\
\hline$F(000)$ & 652 & 1400 \\
\hline Crystal size $\left[\mathrm{mm}^{2}\right]$ & $0.2 \times 0.09 \times 0.08$ & $0.2 \times 0.1 \times 0.1$ \\
\hline $\begin{array}{l}h, k, l \text { ranges } \\
2 \theta \text { range }[]\end{array}$ & $\begin{array}{l}-12 \leq h \leq 12,-22 \leq k \leq 20,-17 \leq l \leq 17 \\
2.311 \text { to } 32.351\end{array}$ & $\begin{array}{l}-34 \leq h \leq 34,-12 \leq k \leq 12,-22 \leq l \leq 20 \\
1.757 \text { 七 } 32.401\end{array}$ \\
\hline Reflections collocted/unique/ ( $\left.R_{\text {line }}\right)$ & $12674 / 4152\left(R_{\mathrm{nz}}=0.0527\right)$ & $262139183\left(R_{\operatorname{lnc}}=0.0646\right)$ \\
\hline $\begin{array}{l}\text { Completeness in } \theta[\%] \\
\text { Absorption correction }\end{array}$ & $\begin{array}{l}94.6 \\
\text { Empirical }\end{array}$ & 99.3 \\
\hline Max, and Min. trensnission & 0.5 and 0.5 & 0.82 and 0.79 \\
\hline $\begin{array}{l}\text { Data/nstrimsprameas } \\
\text { Goothes-of-fit } m F^{2}\end{array}$ & $4152 / 2 / 145$ & $\begin{array}{l}9183228 / 334 \\
0835\end{array}$ \\
\hline $\begin{array}{l}\text { Find } R \text { indices }(I>2 \sigma(I)) \\
R \text { indices (all data) } \\
\left.\text { Lrrgest difference peak and hole [e } \hat{R}^{-3}\right]\end{array}$ & $\begin{array}{l}R_{1}=0.0555, w R_{2}=0.1167 \\
R_{1}=0.1014, w R_{2}=0.1307 \\
+0.459,-0.362\end{array}$ & $\begin{array}{l}R_{1}=0.0477, w R_{2}=0.0562 \\
R_{1}=0.1244, w R_{2}=0.1022 \\
+0.975,-0.597\end{array}$ \\
\hline
\end{tabular}


493 Table 4. Supramolecular interactions $\mathrm{C}-\mathrm{H} \ldots \mathrm{X}(\mathrm{X} 5 \mathrm{Cl}$ or $\mathrm{C})$ parameters for complexes 1 and 2 494

\begin{tabular}{|c|c|c|c|c|}
\hline Complex & D $-\mathrm{H} \cdots \mathbf{A}$ & $\mathbf{H} \cdots \mathbf{A}[\hat{\Lambda}]$ & $\mathrm{D} \cdots[\mathbf{A}]$ & $\mathrm{D}-\mathrm{H} \cdots \mathbf{A}[\mathrm{O}]$ \\
\hline 1 (L.1) & $\begin{array}{c}\mathrm{C} 4-\mathrm{H} 4 \mathrm{~B}-\mathrm{Cl} 2 \mathrm{C} 4 \\
\mathrm{H} 4 \mathrm{C} \cdot \mathrm{Cl}\end{array}$ & $\begin{array}{l}2.819 \\
2.913\end{array}$ & $\begin{array}{l}3.688 \\
3.755\end{array}$ & $\begin{array}{l}150.78 \\
166.96\end{array}$ \\
\hline $2(\mathrm{I} 2)$ & 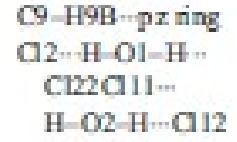 & $\begin{array}{l}2.835 \\
2.633 \\
2.323\end{array}$ & $\begin{array}{l}3.900 \\
3.071 \\
3.372\end{array}$ & $\begin{array}{l}133.33 \\
122.11, \\
121.64\end{array}$ \\
\hline
\end{tabular}

